\title{
A Retrospective Cohort Study of the Potency of lipid-lowering therapy and Race-gender Differences in LDL cholesterol control
}

\author{
Barbara J Turner ${ }^{1 *}$, Christopher S Hollenbeak ${ }^{2}$, Mark Weiner ${ }^{1}$ and Simon SK Tang ${ }^{3}$
}

\begin{abstract}
Background: Reasons for race and gender differences in controlling elevated low density lipoprotein (LDL) cholesterol may be related to variations in prescribed lipid-lowering therapy. We examined the effect of lipid-lowering drug treatment and potency on time until LDL control for black and white women and men with a baseline elevated LDL.

Methods: We studied 3,484 older hypertensive patients with dyslipidemia in 6 primary care practices over a 4-year timeframe. Potency of lipid-lowering drugs calculated for each treated day and summed to assess total potency for at least 6 and up to 24 months. Cox models of time to LDL control within two years and logistic regression models of control within 6 months by race-gender adjust for: demographics, clinical, health care delivery, primary/ specialty care, LDL measurement, and drug potency.

Results: Time to LDL control decreased as lipid-lowering drug potency increased $(P<0.001)$. Black women $(N=$ $1,440)$ received the highest potency therapy $(P<0.001)$ yet were less likely to achieve $L D L$ control than white men $(\mathrm{N}=717)$ (fully adjusted hazard ratio [HR] $0.66[95 \% \mathrm{Cl} 0.56-0.78])$. Black men $(\mathrm{N}=666)$ and white women $(\mathrm{N}=$ 661) also had lower adjusted HRs of LDL control (0.82 [95\% Cl 0.69, 0.98] and 0.75 [95\% Cl 0.64-0.88], respectively) than white men. Logistic regression models of LDL control by 6 months and other sensitivity models affirmed these results.

Conclusions: Black women and, to a lesser extent, black men and white women were less likely to achieve LDL control than white men after accounting for lipid-lowering drug potency as well as diverse patient and provider factors. Future work should focus on the contributions of medication adherence and response to treatment to these clinically important differences.
\end{abstract}

Keywords: dyslipidemia, anticholesterolemic agents, healthcare disparities, survival analysis

\section{Background}

Reducing low density lipoprotein (LDL) cholesterol to levels set by National Cholesterol Education Program Adult Treatment Panel (ATP) III guidelines decreases the risk of death from cardiovascular disease [1] and is cost-effective [2]. Analyses of National Health and Nutrition Examination Surveys (NHANES) from 1999 to 2006 reveal persistent gender and racial differences in meeting these standards [3]. Several studies have implicated physician's treatment of dyslipidemia as contributing to

\footnotetext{
* Correspondence: turner@uthscsa.edu

'Division of General Internal Medicine, University of Pennsylvania, 423

Guardian Drive, Philadelphia, PA, 19104, USA Full list of author information is available at the end of the article
}

these differences in LDL control. Among diabetic patients, black patients were less likely to be prescribed statin therapy than white patients and white men were more likely to achieve LDL control than either women or black men [4]. An analysis of increases in doses of lipidlowering drugs to achieve LDL control reported no difference by race but women had fewer dose increases than men [5]

Most studies of racial differences in achieving LDL control have been cross-sectional and do not consider the potency of prescribed lipid-lowering drugs [6-8]. To evaluate the impact of type and total dose of lipid lowering therapy on racial and gender disparities in LDL control, we adapted a methodology developed previously to assess
C Biomed Central 
the potency of antihypertensive drug therapy [9]. Among primary care patients at increased risk of cardiovascular disease because of hypertension and elevated LDL cholesterol, we hypothesized that race and gender differences in achieving LDL control would be reduced after accounting for lipid-lowering drug potency and baseline LDL values.

\section{Methods}

\section{Study Sample}

Study patients received longitudinal care over a four-year period (1/1/03 through $1 / 1 / 07)$ in 6 primary care practices (one family medicine and 5 general internal medicine) affiliated with an academic medical center in Philadelphia, PA. All practices used EPIC electronic medical record system that offers: demographics, physiologic measures, clinical diagnoses, tobacco use, laboratory data, visit attendance data, prescribed medications, and insurance information. Electronic prescribing is required and free samples prohibited. We linked data on providers' gender, race, and training level (i.e., resident, attending, and nurse practitioner) from certification and departmental sources.

For research on hypertension [10] and cholesterol [11] quality of care, we developed a cohort of hypertensive black or white patients aged $\geq 18[\mathrm{~N}=16,910]$ who have been treated for at least 6 months in a study practice. In this study, we included only older persons whose ATP III LDL goal is $<130 \mathrm{mg} / \mathrm{dl}$ or $<100$ for those with cardiovascular disease, diabetes, or a diabetes equivalent condition [12] (Figure 1). All study subjects were followed in study practices at least 6 months after their first high LDL.

\section{Outcome Variables}

The primary study outcome was the time in days from the initial elevated LDL value after 1/03 until LDL control per ATP III guidelines (i.e., < $130 \mathrm{mg} / \mathrm{dl}$ if moderate risk or < $100 \mathrm{mg} / \mathrm{dl}$ if high risk [1]) was achieved. We also examined the proportion of patients who achieved control within 6 months after the high baseline LDL.

\section{Predictor Variables}

Our primary predictor was a four level race-gender variable (i.e., women and men grouped as white or black). Demographics included age and median household annual income based on residence zip code in 2000 United States census data (http://www.census.gov). We extracted all prescriptions (i.e., statins, fibrates, nicotinic acid derivatives, bile acid sequestrants, and cholesterol absorption inhibitors) during the study timeframe. To calculate the daily potency of lipid-lowering therapy, we assigned a weight to each lipid-lowering drug and dose based on published data and reports on reductions in LDL cholesterol (Table 1) [13-15]. A weight of 1.00 was assigned to atorvastatin $10 \mathrm{mg}$ per day (the most frequently prescribed dose) that reduces LDL cholesterol by a mean of $34-38 \%$. We then determined the relative weights for all prescribed lipid-lowering drugs and doses based on the mean reduction in LDL. For example, assuming a $36 \% \mathrm{LDL}$ reduction for atorvastatin $10 \mathrm{mg}$ (the midpoint for 34-38\%), pravastatin $10 \mathrm{mg}$, which has an expected LDL reduction of $21.5 \%$, received a weight of $.215 / .36=0.597$. Daily potency weights for drug combinations such as atorvastatin plus ezetimibe were summed for each day.

To calculate total lipid-lowering drug potency and allow for the dynamic nature of our follow-up, we adapted a method developed by Bailey and colleagues [9] to assess antihypertensive drug potency and previously used in our research [16]. First, the duration of each prescription was calculated from the number of prescribed lipid-lowering medication pills and refills and, in case of overlapping prescriptions, we counted the most recent. To calculate total potency, we multiplied the potency weight of each day's lipid-lowering therapy by days of prescribed drug(s). For example, a patient taking atorvastatin $10 \mathrm{mg}$ (daily potency weight $=1$ ) for 60 days was assigned a value of 60 for total potency but the same value would be assigned to a $10 \mathrm{mg}$ dose of pravastatin (daily potency weight $=0.597$ ) prescribed for 101 days. Persons who received no treatment at all had a total potency of 0 . We created an indicator for the presence of lipid-lowering therapy at the start of the study timeframe. For analyses of prescribed lipid-lowering therapy, we examined categorical and continuous specifications of drug potency.

We categorized baseline elevated LDL cholesterol by quartile. We also created indicators for the number of LDL determinations in the first 6 months after the baseline elevated LDL. Other clinical measures include: diabetes (i.e. ICD-9-CM 250.xx at two visits or hemoglobin A1c $\geq 7 \mathrm{mg} / \mathrm{dl}$ ); renal insufficiency (i.e., creatinine $>2$ ); other vascular diseases (i.e. coronary artery disease, peripheral vascular disease, cerebrovascular disease); and 28 non-cardiovascular comorbidities (e.g. arthritis, gastroesophageal reflux/gastritis) as reported previously [10]. Smoking status was categorized as currently smoking, not smoking, or not recorded. We calculated the maximum number of concurrent antihypertensive drugs prescribed within the study timeframe.

Health care variables included: insurance type and attendance to scheduled primary care visits within a 6year interval (i.e., 1/02 to $1 / 07$ categorized in quartiles). Primary care provider characteristics were: gender, race, type, and workload (in quartiles) based on the maximum annual patient visits in the study timeframe.

\section{Analyses}

The cohort was followed for at least 6 months to a maximum of 24 months to determine if LDL cholesterol 


\section{Patient N}

Hypertensive patients aged 18 or older, black or white race, In a study practice from 01/01/2003-1/1/2007

Exclusions:

Missing race, age, gender, or income [N=921]

No LDL cholesterol determination $\quad[\mathrm{N}=1,921]$

No elevated LDL cholesterol

$[\mathrm{N}=8,640]$
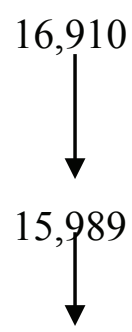
Men aged $<45$ or women $<55$
$[\mathrm{N}=1,340]$
Treated for hypercholesterolemia $\quad[\mathrm{N}=261]$
before $01 / 01 / 2003$

Only visits missing provider type $\quad[\mathrm{N}=343]$

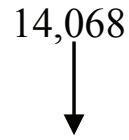

Figure 1 Derivation of Study Cohort of Older Hypertensive Patients with Dyslipidemia.

control per ATP III guidelines was achieved. We conducted two types of analyses. Our first outcome was time until LDL cholesterol control examined using survival analysis methods with Cox proportional hazards models, censoring if a subject did not achieve LDL control by 6 months after the last visit or the end of the study. We examined Kaplan-Meier curves of time until LDL control for all key variables as well as proportional

Table 1 Relative Daily Potency of the HMG-CoA Reductase Inhibitors [Statins] and Non-statin Lipid-lowering Drugs

\begin{tabular}{cccc}
\hline Drug & $\begin{array}{c}\text { Daily dose range } \\
\text { in study population }\end{array}$ & $\begin{array}{c}\text { Effect on LDL Cholesterol* } \\
\text { [\% decrease] }\end{array}$ & Relative potencyt of lowest and highest dose \\
\hline Statins & $5-80 \mathrm{mg}$ & $32-50 \%$ & $0.89,1.39$ \\
Atorvastatin & $20-80 \mathrm{mg}$ & $22-35 \%$ & $0.61,0.97$ \\
Fluvastatin & $10-120 \mathrm{mg}$ & $21-50 \%$ & $0.58,1.39$ \\
Lovastatin & $5-320 \mathrm{mg}$ & $15-40 \%$ & $0.42,1.11$ \\
Pravastatin & $2.2-60 \mathrm{mg}$ & $39-60 \%$ & $1.08,1.67$ \\
Rosuvastatin & $5-160 \mathrm{mg}$ & $22-50 \%$ & $0.61,1.39$ \\
Simvastatin & & & $0.10,0.25$ \\
Non-Statins & $4-16 \mathrm{~g}$ & $4-9 \%$ & $0.14,0.28$ \\
Cholestyramine & $625-3750 \mathrm{mg}$ & $5-10 \%$ & $0.14,0.28$ \\
Colesevelam & $1-10 \mathrm{~g}$ & $5-10 \%$ & $0.28,0.56$ \\
Colestipol & $5-30 \mathrm{mg}$ & $10-20 \%$ & $0.14,0.28$ \\
Ezetimibe & $27-320 \mathrm{mg}$ & $5-10 \%$ & $0.14,0.28$ \\
Fenofibrate & $300-1200 \mathrm{mg}$ & $5-10 \%$ & $0.10,0.25$ \\
Gemfibrazole & $250-3000 \mathrm{mg}$ & $4-9 \%$ & $0.10,0.14$ \\
Niacin & $3-12 \mathrm{mg}$ & $4-5 \%$ & \\
Omega & & & \\
\hline
\end{tabular}

* References 13-15.

† Atorvastatin $10 \mathrm{mg}$ per day assigned a daily potency weight of 1 . 
hazards assumptions. For the second outcome of LDL control by 6 months after the initial elevated LDL, we estimated logistic regression models.

Among treated persons, lipid-lowering drug potency was examined both as a continuous variable and in two categories: low (a mean daily potency weight of 1 for less than half of the mean number of treated days $[\mathrm{n}=$ 450]) versus high (a mean potency weight of 1 for more than half of the mean treated days). Persons with no treatment were considered as a third category.

In a series of Cox proportional hazards models, we sequentially added 5 sets of variables to assess changes in the hazard ratios for each race-gender group versus white men. The sets of variables were: demographics; clinical; health care; primary care provider and specialty care; baseline LDL, frequency of LDL checks, and lipid-lowering drug potency. We included an indicator of time [days] since the initial LDL was obtained. We also fit parametric Weibull survival models with physician level frailties to examine the effect of clustering on primary care provider but the conclusions were similar to reported models and are not shown.

The logistic regression models adjust for all study variables. Sensitivity analyses examined stability of the genderrace association in logistic models for subsets of subjects with the same insurance (Medicare or commercial), neighborhood income level, or age group. We also estimated models among only subjects with diabetes or another condition warranting a lower $[<100 \mathrm{mg} / \mathrm{dl}] \mathrm{LDL}$ goal.

\section{Role of the Funding Source}

Research funding was provided by Pfizer, Inc. to the University of Pennsylvania. Authors from the University of Pennsylvania and Penn State College of Medicine conducted all analyses and wrote the manuscript. One author is a Pfizer employee, but he did not have direct access to study data. This author obtained study funding, contributed to the study design and reviewed the manuscript. Pfizer had no role in the decision to submit the manuscript for publication. This project was approved by the University of Pennsylvania Institutional Review Board.

\section{Results}

The derivation of the study cohort is shown in Figure 1. Eighty-nine percent of patients aged 18 or older had baseline LDL cholesterol determination and, of these, 39\% had an elevated level. Among the 3,484 study subjects with elevated LDL cholesterol, women were older than men and black subjects had lower income levels than white subjects. Women were more likely to be Medicare-enrolled than men and black patients were more likely to be Medicaidenrolled than white patients (Table 2).

Women had higher baseline LDL levels than men but, within each gender group, the mean LDL values did not differ by race (Table 2). Time until a follow-up LDL determination did not significantly differ by race-gender group $(P=0.10)$ but men had significantly more LDL determinations within 6 months after the baseline elevated LDL cholesterol than women. LDL control at 6 months after baseline differed significantly by racegender group but was poorest for black women.

Higher proportions of black patients were diagnosed with vascular disease, diabetes, or renal insufficiency than white patients. Black women had more non-cardiovascular comorbid conditions than the other race-gender groups. Current tobacco use was more prevalent in black men. Fifty-five percent of the cohort was prescribed lipid-lowering therapy during the study timeframe; black women were the most likely to be treated of the four race-gender groups. Among those who were treated, black women and men were prescribed more potent lipid-lowering medications than white women or men. Black women were also treated for more days than the other gender-race groups and had higher lipid-lowering drug potency.

In regard to health care, white patients had fewer annual arrived visits but black patients were less adherent to scheduled visits. Black patients were prescribed more antihypertensive medications. Most of the 202 primary care providers were white and more than half were women. Attending physicians delivered care to the majority of patients but treated fewer black patients.

Higher lipid-lowering drug potency was associated with shorter time to LDL control $[\mathrm{P}<0.001]$ (Figure 2). Additional analyses showed that patients who were being prescribed lipid-lowering therapy at the time of the baseline elevated LDL did not differ in time to LDL control from those on no therapy at baseline $(\mathrm{P}=0.83)$.

However, the mean unadjusted time until LDL control differed significantly $(P<0.001)$ by gender-race group: 540 days for black women, 505 days for white women, 510 days for black men, and 444 days for white men (Figure 3). Note that these times are shorter than the total time on therapy reported in Table 2 since patient remained on lipid lower therapy even after achieving LDL control. At each potency level, black women had a lower unadjusted hazard of achieving control than white men (Figure 4). Compared with white men, the unadjusted hazards of achieving LDL control were reduced by $39 \%$ for black women and by $25 \%$ for black men and $28 \%$ for white women (Table 3). Adjusting for demographic, clinical, health care and provider characteristics produced little change in these results. Adjusting for baseline LDL cholesterol, frequency of LDL checks (continuous), and lipid-lowering drug potency moderated these effects somewhat but the hazards of LDL control remained significantly lower for all three groups versus white men (Table 3). In the final model, high potency lipid-lowering 
Table 2 Characteristics of Four Race-Gender Groups of Primary Care Hypertensive Patients with High Baseline LDL Cholesterol

\begin{tabular}{|c|c|c|c|c|c|}
\hline Characteristic & $\begin{array}{c}\text { Black } \\
\text { women } \\
(\mathrm{N}=1,440)\end{array}$ & $\begin{array}{c}\text { Black } \\
\text { men } \\
(\mathrm{N}=666)\end{array}$ & $\begin{array}{l}\text { White women } \\
\qquad(\mathrm{N}=661)\end{array}$ & $\begin{array}{c}\text { White } \\
\text { men } \\
(\mathrm{N}=717)\end{array}$ & P Value \\
\hline Baseline LDL cholesterol [mg/dl], mean [SD] & $142.8(29.9)$ & $138.9(28.0)$ & $144.0(24.3)$ & $137.2(23.4)$ & $<0.001$ \\
\hline LDL control by 6 months after baseline, $\%$ & 16.8 & 18.9 & 20.3 & 28.5 & $<0.001$ \\
\hline LDL cholesterol tests within 6 months after baseline, N [SD] & $0.85(0.75)$ & $0.90(0.79)$ & $0.80(0.77)$ & $0.92(0.90)$ & 0.026 \\
\hline \multicolumn{6}{|l|}{ Sociodemographic } \\
\hline Age [years], mean [SD] & $68.4(9.7)$ & $61.4(11.1)$ & $68.4(9.9)$ & $62.3(10.5)$ & $<0.001$ \\
\hline Median income in zipcode of residence, mean \$ [SD] & $28,360(10,904)$ & $30,692(12,825)$ & $\begin{array}{c}57,004 \\
(23,790)\end{array}$ & $58,680(23,464)$ & $<0.001$ \\
\hline \multicolumn{6}{|l|}{ Insurance type [\%] } \\
\hline Commercial & 46.4 & 60.7 & 57.5 & 72.5 & $<0.001$ \\
\hline Medicaid & 17.4 & 14.9 & 2.0 & 2.2 & \\
\hline Medicare & 35.4 & 22.8 & 40.2 & 24.8 & \\
\hline Self pay & 0.8 & 1.7 & 0.3 & 0.4 & \\
\hline \multicolumn{6}{|l|}{ LDL Cholesterol } \\
\hline Baseline LDL [mg/dl], mean [SD] & $142.8(29.9)$ & $138.9(28.0)$ & $144.0(24.3)$ & $137.2(23.4)$ & $<0.001$ \\
\hline LDL tests within 6 months mean [SD] & $0.85(0.75)$ & $0.90(0.79)$ & $0.80(0.77)$ & $0.92(0.90)$ & 0.026 \\
\hline LDL control by 6 months after baseline, $\%$ & 16.8 & 18.9 & 20.3 & 28.5 & $<0.001$ \\
\hline \multicolumn{6}{|l|}{ Clinical } \\
\hline Vascular disease, \% & 30.1 & 28.2 & 21.2 & 21.1 & $<0.001$ \\
\hline Diabetes, \% & 41.5 & 46.2 & 19.5 & 31.1 & $<0.001$ \\
\hline Renal insufficiency, \% & 13.3 & 21.9 & 3.3 & 9.6 & $<0.001$ \\
\hline Unrelated comorbidities, \# & 6.3 & 5.4 & 5.5 & 4.9 & $<0.001$ \\
\hline \multicolumn{6}{|l|}{ Tobacco use, \% } \\
\hline Current & 11.2 & 14.9 & 5.0 & 10.3 & $<0.001$ \\
\hline No & 55.3 & 45.2 & 70.8 & 54.7 & \\
\hline Not recorded & 33.5 & 39.9 & 24.2 & 35.0 & \\
\hline \multicolumn{6}{|l|}{ Lipid-lowering Drug Therapy } \\
\hline Treated (\%) & $57.4 \%$ & $54.7 \%$ & $52.5 \%$ & $53.7 \%$ & 0.134 \\
\hline Potency per day of treatment, mean (SD) & $0.96(0.26)$ & $0.97(0.25)$ & $0.90(0.25)$ & $0.91(0.3)$ & $<0.001$ \\
\hline Duration of treatment, days, mean (SD) & $964.5(550.3)$ & $919.6(537.6)$ & $887.3(544.9)$ & $911.7(548.4)$ & 0.01 \\
\hline \multicolumn{6}{|l|}{ Total potency, categorical (treated only) } \\
\hline None, $\%$ & 42.6 & 45.4 & 47.5 & 46.3 & \\
\hline Lower $[\leq 840], \%$ & 26.5 & 28.5 & 26.5 & 30.3 & 0.007 \\
\hline Higher [> 840],\% & 31.0 & 26.1 & 26.0 & 23.4 & \\
\hline \multicolumn{6}{|l|}{ Health Care } \\
\hline Primary care arrived visits per year, mean (SD) & $6.3(4.2)$ & $6.5(4.6)$ & $5.8(3.7)$ & $5.7(6.1)$ & 0.002 \\
\hline Kept $<60 \%$ of scheduled visits, $\%$ & 19.7 & 20.7 & 13.0 & 10.2 & $<0.001$ \\
\hline Maximum concurrent anti-hypertensive drugs, mean N (SD) & $2.5(1.3)$ & $2.3(1.3)$ & $1.9(1.1)$ & $1.8(1.2)$ & $<0.001$ \\
\hline \multicolumn{6}{|l|}{ Provider (N) } \\
\hline \multicolumn{6}{|l|}{ Race, \% } \\
\hline White (157) & 60.7 & 62.5 & 90.6 & 91.2 & $<0.001$ \\
\hline Asian (27) & 11.7 & 7.7 & 3.3 & 2.5 & \\
\hline Other Minority (18) & 27.6 & 30.0 & 6.1 & 6.3 & \\
\hline \multicolumn{6}{|l|}{ Gender, \% } \\
\hline Female (110) & 60.3 & 47.3 & 53.7 & 31.3 & $<0.001$ \\
\hline \multicolumn{6}{|l|}{ Type, \% } \\
\hline Attending (74) & 56.7 & 61.0 & 69.6 & 73.1 & $<0.001$ \\
\hline Resident (105) & 17.0 & 16.2 & 7.9 & 8.4 & \\
\hline Nurse practitioner/Physician assistant (23) & 26.3 & 22.8 & 22.5 & 18.6 & \\
\hline Annual arrived visits to & 1916.8 & 1980.1 & 2009.0 & 2202.7 & $<0.001$ \\
\hline provider, mean N (SD) & $(1464.7)$ & $(1454.6)$ & $(1207.5)$ & $(1404.4)$ & \\
\hline
\end{tabular}




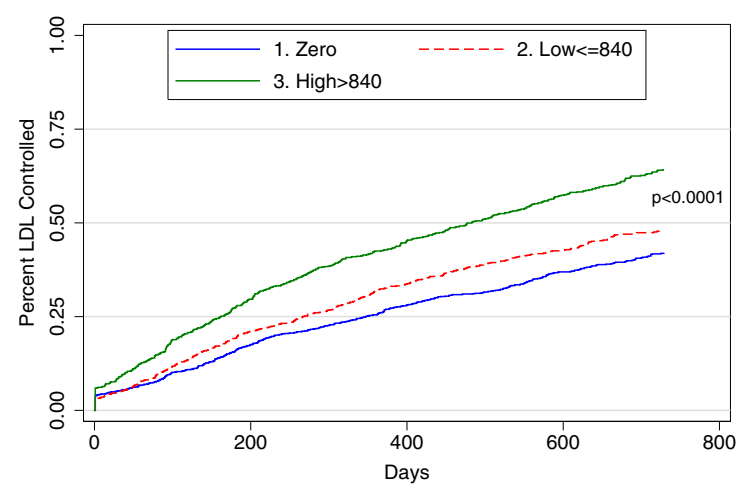

Figure 2 Time Until LDL Cholesterol Control for Four RaceGender Groups.

therapy showed one of the strongest positive associations with LDL control of all covariates with an adjusted hazard of 1.85 (95\% CI: 1.63, 2.1) for high potency relative no treatment (Table 4). Racial disparities in LDL control were most evident for subjects receiving higher potency therapy (Figure 5). In separate models among persons who only have diabetes or another risk factor with a lower LDL control standard $(<100 \mathrm{mg} / \mathrm{dl})$, gender-race differences was similar to those in the entire cohort.

Analysis of the adjusted odds of LDL control by 6 months showed similar associations with a fully adjusted odds ratios for black women of 0.53 (95\% CI: 0.40 0.71 ), for white women of 0.64 ( $95 \%$ CI: $0.49-0.85)$, for black men of 0.65 (95\% CI: 0.48 - 0.89) versus white men. Even though black patients were more likely to have diabetes and other conditions that require a lower LDL goal $(<100 \mathrm{mg} / \mathrm{dl})$, analyses restricted to only

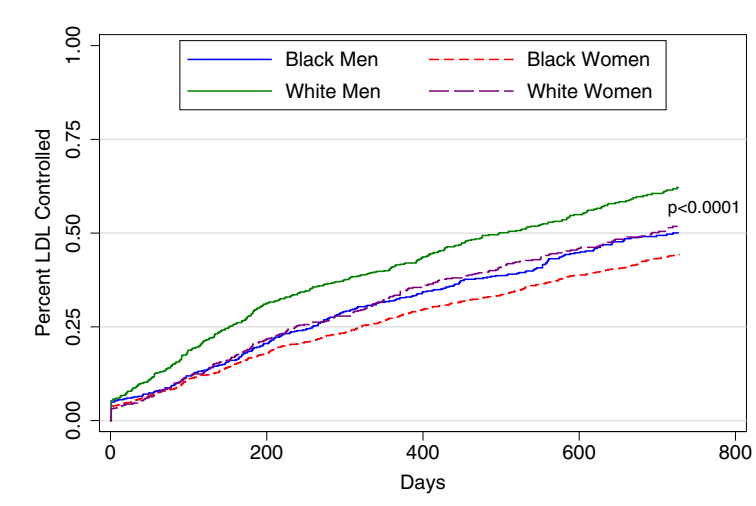

Figure 3 Hazard Ratios for Time Until LDL Cholesterol Control for Four Race-Gender Groups by Categories of Total Potency of Lipid-lowering Drug Therapy. ${ }^{*}$ Categories: No Treatment; Low = 1840 potency days; High $=>840$ total lipid-lowering potency days [see methods], Adjusted for all the variables in Appendix Table 2.

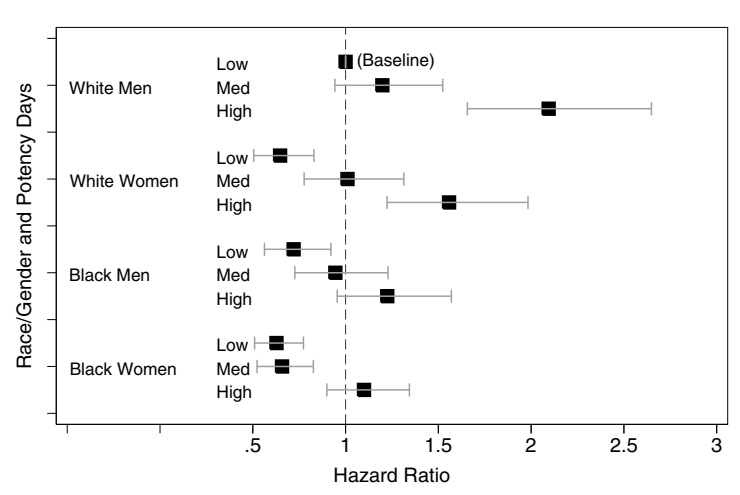

Figure 4 Hazard Ratio for Achieving LDL Control Stratified by Race and Gender.

patients with these conditions showed similar odds ratios for each of the gender-race groups. Additional stratified analyses showed similar gender-race effects among: persons with Medicare insurance or commercial insurance, among persons with low income, and among persons with the same age category.

\section{Discussion}

The US National Ambulatory Medical Care Survey from 2005 revealed marked inequities in assessment and management of dyslipidemia by respondents' race-ethnicity [17]. Among nearly 3,500 older primary care patients with hypertension and dyslipidemia, we use a novel approach to assessing the potency of prescribed lipid lowering therapy as a potential explanatory factor contributing to these inequities. Contrary to other studies that reported less treatment for dyslipidemia for women $[18,19]$ or fewer lipid-lowering dose changes among treated women [5], the women in our study cohort were more likely to be treated for hyperlipidemia and prescribed more intensive lipid lowering therapy than men the same racial group. Indeed, black study women were the most likely to be treated for dyslipidemia and, when treated, were prescribed more potent treatment than black men, white women and white men. Mark et al. reported that black patients were less likely to have their lipid-lowering drugs switched, augmented, or titrated but did not examine achievement of LDL control goals [20]. In contrast, we find that, even though black patients received more intensive treatment, racial differences in achieving LDL cholesterol targets persisted. After two years, two-thirds of white men achieved LDL control versus only $50 \%$ or less of black men and women as well as white women. These sustained differences in LDL control are clinically significant [2] and may play a role in observed disparities in clinical outcomes of cardiovascular disease [21]. 
Table 3 Association of Race-Gender Groups with Time until LDL Cholesterol Control in Cox Proportional Hazards Models Adjusted for Sequentially Added Sets of Variables

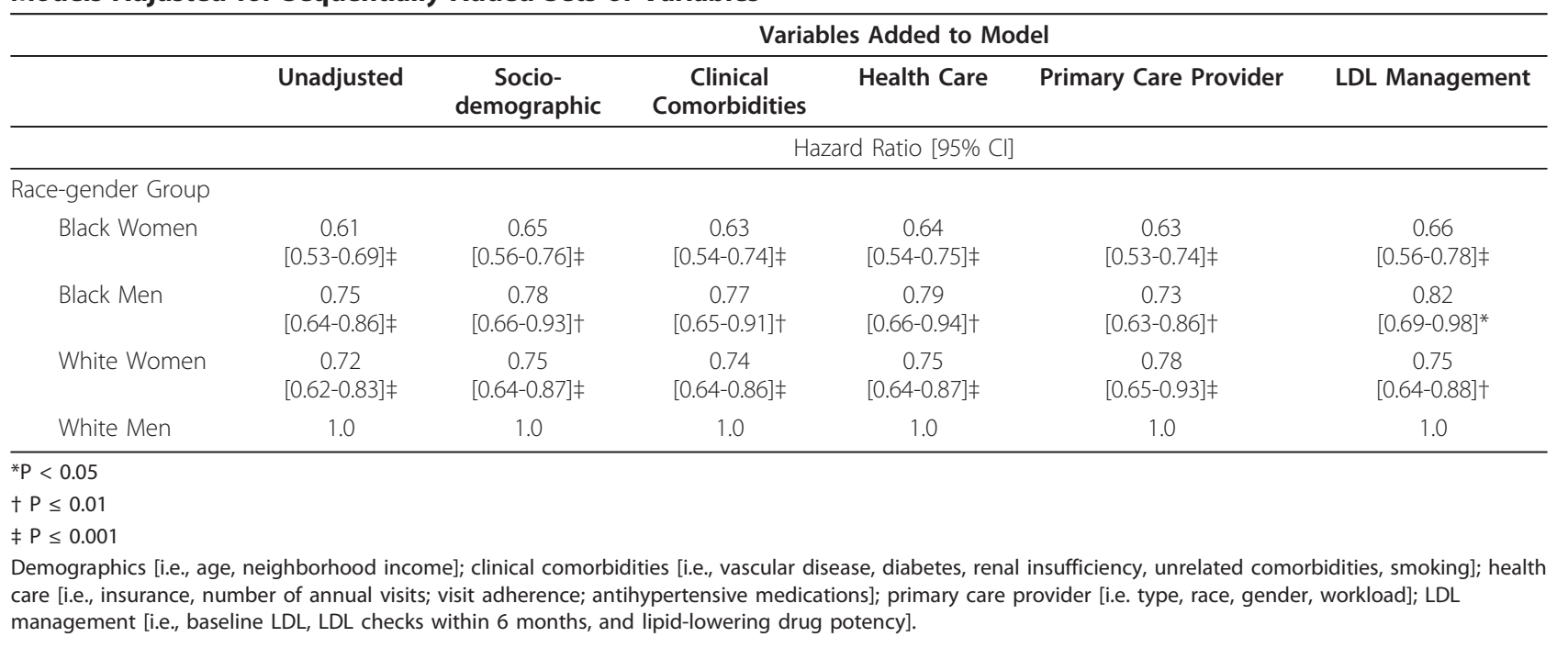

Our study focuses on the type and strength of prescribed lipid-lowering therapy but we could not evaluate the impact of counseling about a low cholesterol diet or adherence to the medication. In regard to unmeasured patient-related factors, inherent genetic differences may attenuate response to lipid-lowering therapy. However, in more controlled circumstances such as clinical trials, women and black men have responded to lipid-lowering therapy similarly to white men [22-24] and women [25]. Differences in adherence to lipid-lowering therapy may explain some of these associations; Chan and colleagues reported that men were more adherent to statins than women as were persons who lived in predominantly nonblack compared with primarily black neighborhoods [26]. Among Medicaid enrollees, Litaker reported that black patients were $25 \%$ less likely to persist in taking lipid-lowering drugs than white patients [27]. Statin nonadherence may reflect deficient office based monitoring [28]; in our analysis, we accounted for adherence to office visits and frequency of LDL determinations.

Research has also implicated negative patient attitudes about lipid-lowering therapy $[29,30]$ and limited understanding of the need for long-term therapy [29,31]. Increased patient education by the physician or an allied health personnel has been endorsed to address these attitudinal and knowledge barriers [32]. Our analyses did not adjust for restrictive pharmacy benefit plans or cost barriers to achieving LDL control [33]. Fortunately, generic statins have greatly reduced the cost of therapy [34] as have value-based drug benefit programs [35]. In sensitivity analyses, gender-race differences persisted among patients with Medicare insurance or those with commercial insurance. Chan and colleagues reported that adjusting for patient and physician characteristics as well as out-of- pocket costs did not significantly explain the variation in adherence to statins [26].

Overall, our cohort was prescribed relatively low potency lipid-lowering therapy, the equivalent of approximately simvastatin $20 \mathrm{mg}$ per day. In a Norwegian study, the mean dose of prescribed lipid-lowering drugs was $25 \mathrm{mg}$ for simvastatin and $22 \mathrm{mg}$ for atorvastatin but, there too, doses were low [36]. Based on a recent simulation study, more tailored statin treatment would save lives if physicians initiated treatment with simvastatin $40 \mathrm{mg}$ for persons at intermediate cardiovascular risk dose and atorvastatin $40 \mathrm{mg}$ for persons at high risk [37]. The reasons for the conservative dosing of lipid-lowering drugs for our cohort are unknown but may reflect concerns about side effects at higher doses.

Our study has other limitations. First, the gender-race groups differed in multiple characteristics but, the differences in goal attainment persisted even when restricting the study analyses to persons with diabetes or other risk factor that requires a lower LDL standard. Second, our measure of total potency is the same for persons who take high doses for a short time or low doses for a longer time. However, racial differences persisted among only patients prescribed higher potency treatment. Third, the total pill burden may have negatively affected acceptance or persistence in taking lipid-lowering therapy. We did consider the number of prescribed antihypertensive drugs as well as the number of comorbidities that require more medications. In other analyses, patients with a greater number of concurrent medications were more likely to be adherent to statin therapy [38]. Fourth, we also could not consider the effect of therapeutic substitutions that can affect adherence [39]. Fifth, specialists might have prescribed these drugs but they share the 
Table 4 Final Model of Time until LDL Cholesterol Control

\begin{tabular}{|c|c|c|c|c|}
\hline \multirow[b]{2}{*}{ Characteristic } & \multirow{2}{*}{$\begin{array}{c}\text { Hazard } \\
\text { Ratio }\end{array}$} & \multicolumn{2}{|c|}{$95 \% \mathrm{Cl}$} & \multirow[b]{2}{*}{$P$ value } \\
\hline & & Lower & Upper & \\
\hline \multicolumn{5}{|l|}{ Gender-race } \\
\hline Black women & 0.66 & 0.56 & 0.78 & $<0.0001$ \\
\hline Black men & 0.82 & 0.69 & 0.98 & 0.029 \\
\hline White women & 0.75 & 0.64 & 0.88 & $<0.0001$ \\
\hline \multicolumn{5}{|l|}{ Baseline LDL cholesterol (quartile) } \\
\hline Second & 0.89 & 0.78 & 1.01 & 0.082 \\
\hline Third & 0.67 & 0.58 & 0.77 & $<0.0001$ \\
\hline Fourth & 0.48 & 0.42 & 0.56 & $<0.0001$ \\
\hline \multicolumn{5}{|l|}{ Total lipid-lowering drug potency } \\
\hline Low & 1.23 & 1.08 & 1.41 & 0.001 \\
\hline High & 1.85 & 1.63 & 2.1 & $<0.0001$ \\
\hline \multicolumn{5}{|l|}{ LDL checks in first 6 months } \\
\hline $1-2$ & 2.79 & 2.33 & 3.35 & $<0.0001$ \\
\hline $3+$ & 4.41 & 3.58 & 5.44 & $<0.0001$ \\
\hline \multicolumn{5}{|l|}{ Age [years] } \\
\hline $61-70$ & 1.1 & 0.98 & 1.25 & 0.114 \\
\hline $71-80$ & 1.28 & 1.11 & 1.47 & 0.001 \\
\hline$>80$ & 1 & 0.84 & 1.21 & 0.96 \\
\hline Median neighborhood (per \$1000 increase) & 1 & 1 & 1.01 & 0.016 \\
\hline \multicolumn{5}{|l|}{ Smoking status } \\
\hline Current & 0.99 & 0.84 & 1.18 & 0.934 \\
\hline Not reported & 1.04 & 0.93 & 1.17 & 0.512 \\
\hline Vascular disease & 0.8 & 0.7 & 0.92 & 0.001 \\
\hline Unrelated comorbidities (per comorbidity) & 1.04 & 1.02 & 1.06 & $<0.0001$ \\
\hline Diabetes & 0.81 & 0.72 & 0.9 & $<0.0001$ \\
\hline Chronic renal insufficiency & 1.26 & 1.05 & 1.52 & 0.012 \\
\hline \multicolumn{5}{|l|}{ Insurance type } \\
\hline Medicaid & 0.87 & 0.72 & 1.04 & 0.128 \\
\hline Medicare & 0.97 & 0.86 & 1.1 & 0.623 \\
\hline Self pay & 0.85 & 0.42 & 1.71 & 0.641 \\
\hline High patient adherence to visits & 1.31 & 1.13 & 1.51 & $<0.0001$ \\
\hline Antihypertensive drugs (N) & 0.98 & 0.93 & 1.02 & 0.299 \\
\hline \multicolumn{5}{|l|}{ Provider type } \\
\hline Resident & 1.15 & 0.96 & 1.38 & 0.117 \\
\hline Other clinician & 1.01 & 0.86 & 1.19 & 0.897 \\
\hline \multicolumn{5}{|l|}{ Provider race } \\
\hline Asian & 1.07 & 0.85 & 1.33 & 0.57 \\
\hline Black or other & 0.99 & 0.84 & 1.16 & 0.877 \\
\hline Female provider & 1.03 & 0.9 & 1.18 & 0.645 \\
\hline \multicolumn{5}{|l|}{ Provider workload (quartile of annual visits) } \\
\hline Second & 1.02 & 0.88 & 1.19 & 0.788 \\
\hline Third & 0.96 & 0.82 & 1.12 & 0.58 \\
\hline Fourth & 0.94 & 0.78 & 1.14 & 0.535 \\
\hline \multicolumn{5}{|l|}{ Patient visits (quartile of annual visits) } \\
\hline Second & 1.01 & 0.88 & 1.16 & 0.896 \\
\hline Third & 1.09 & 0.95 & 1.25 & 0.24 \\
\hline Fourth & 1.01 & 0.87 & 1.18 & 0.867 \\
\hline
\end{tabular}



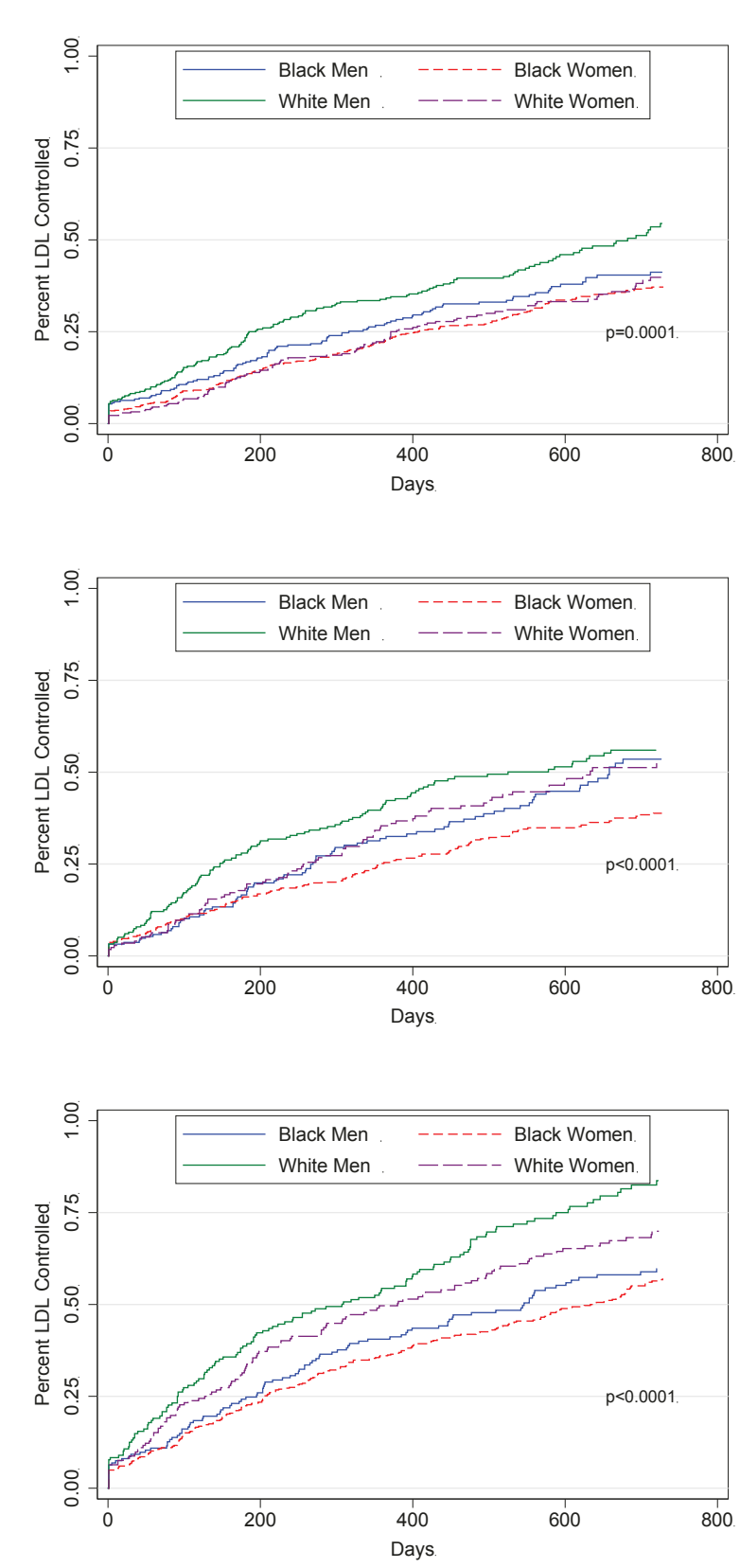

Figure 5 Time to LDL Control Stratified by Race, Gender, and Potency of LDL Therapy.

same electronic medical record and medication reconciliation is required at each primary care visit.

Our study does not support the theory that differences in receiving lipid-lowering therapy or, when treated, potency of the prescribed therapy can account for widely observed racial- and gender-based differences in LDL cholesterol control. These data should direct attention to evaluating and addressing barriers to lipid-lowering drug adherence especially among black patients regardless of gender and white women. Promising approaches have been reported. For example, a health professional counseling by telephone significantly increased persistence with lipid-lowering medication but still only half of the subjects achieved LDL control within a year [40]. Finally, our study also reveals that primary care physicians may be prescribing sub-optimal doses of statin therapy demonstrating important opportunities to improve quality of care.

\section{Conclusions}

In this study of 3,484 older hypertensive patients with dyslipidemia in 6 primary care practices, we found that black women, in spite of receiving the highest potency therapy, were less likely to achieve LDL control than white men. To a lesser extent, black men and white women were also less likely to achieve LDL control than white men after accounting for lipid-lowering drug potency as well as diverse patient and provider factors. Future work should focus on the contributions of medication adherence and response to treatment to these clinically important differences.

\section{Author details}

'Division of General Internal Medicine, University of Pennsylvania, 423 Guardian Drive, Philadelphia, PA, 19104, USA. ${ }^{2}$ Departments of Surgery and Public Health Sciences, Penn State College of Medicine, 600 Centerview Drive, A210, Hershey, PA, 17033, USA. ${ }^{3}$ Pfizer, Inc., 235 East 42nd Street, New York, NY, 10017, USA.

\section{Authors' contributions}

BT conceived of the study and participated in its design, coordination, conduct, analysis, and drafted the manuscript. MW participated in the design of the study, conduct, and the interpretation of results. $\mathrm{CH}$ participated in the design of the study and performed the statistical analysis. ST participated in the conception and design of the study and secured funding. All authors revised the manuscript for content and read and approved the final manuscript.

\section{Competing interests}

This study was funded by a research grant from Pfizer, Inc., to the University of Pennsylvania. BT, $\mathrm{CH}$, and $\mathrm{MW}$ received salary support from this funding. At the time the study was conducted, ST was an employee of Pfizer, Inc., and owned Pfizer stocks and stock options. None of the authors have any non-financial competing interests.

Received: 2 November 2010 Accepted: 30 September 2011 Published: 30 September 2011

\section{References}

1. Expert Panel on Detection, Treatment of High Blood Cholesterol in Adults: Executive summary of the Third Report of The National Cholesterol Education Program [NCEP] Expert Panel on Detection, Evaluation, And Treatment of High Blood Cholesterol In Adults [Adult Treatment Panel III]. JAMA 2001, 285(19):2486-97.

2. Pletcher MJ, Lazar L, Bibbins-Domingo $K$, et al: Comparing impact and cost effectiveness of primary prevention strategies for lipid-lowering. Ann Intern Med 2009, 150:243-54.

3. Ford ES, Li C, Pearson WS, Zhao G, et al: Trends in hypercholesterolemia, treatment and control among United States adults. Int J Cardiol 2008, [Epub].

4. Sequist TD, Adams A, Zhang F, et al: Effect of quality improvement on racial disparities in diabetes care. Arch Intern Med 2006, 166:675-81. 
5. Persell SD, Maviglia SM, Bates DW, et al: Ambulatory hypercholesterolemia management in patients with atherosclerosis. Gender and race differences in processes and outcomes. J Gen Intern Med 2005, 20(2):123-30.

6. Gouni-Berthold I, Berthold HK, Mantzoros CS, et al: Sex disparities in the treatment and control of cardiovascular risk factors in type 2 diabetes. Diabetes Care 2008, 31(7):1389-91.

7. O'Meara JG, Kardia SL, Armon JJ, et al: Ethnic and sex differences in the prevalence, treatment, and control of dyslipidemia among hypertensive adults in the GENOA study. Arch Intern Med 2004, 164(12):1313-8.

8. Ferrara A, Mangione CM, Kim C, et al: Sex disparities in control and treatment of modifiable cardiovascular disease risk factors among patients with diabetes: Translating Research Into Action for Diabetes [TRIAD] Study. Diabetes Care 2008, 31(1):69-74.

9. Bailey KR, Grossardt BR, Graves JW: Novel use of Kaplan-Meier methods to explain age and gender differences in hypertension control rates. Hypertension 2008, 51:841-7.

10. Turner BJ, Hollenbeak CS, Weiner M, et al: Effect of unrelated comorbid conditions on hypertension management. Ann Intern Med 2008, 148:578-86.

11. Lagu T, Weiner MG, Hollenbeak CS, Roberts CS, Schwartz JS, Turner BJ: The impact of concordant and discordant conditions on the quality of care for hyperlipidemia. J Gen Intern Med 2008, 23(8):1208-13.

12. Grundy SM, Cleeman Jl, Merz CN, et al: Implications of recent clinical trials for the National Cholesterol Education Program Adult Treatment Panel III guidelines. Circulation 2004, 110(2):227-39.

13. Hou R, Goldberg AC: Lowering low-density lipoprotein cholesterol: statins, ezetimibe, bile acid sequestrants, and combinations: comparative efficacy and safety. Endocrinol Metab Clin N Am 2009, 38:79-97.

14. Consumer Reports Health.org: Evaluating drugs to treat high cholesterol and heart disease: comparing effectiveness, safety, and price [http://www. consumerreports.org/health/resources/pdf/best-buy-drugs/StatinsUpdateFINAL.pdf], accessed July 21,2011.

15. Sharma M, Ansari MT, Abou-Setta AM, et al: Systematic review: comparative effectiveness and harms of combination therapy and monotherapy for dyslipidemia. Ann Intern Med 2009, 151(9):622-30.

16. Gross $R$, Weiner $M G$, et al: Racial disparities in hypertension control, but not treatment intensification. Am J Hypertens 2010, 23(1):54-61.

17. Willson MN, Neumiller JJ, Sclar DA, Robison LM, Skaer TL: Ethnicity/race, use of pharmacotherapy, scope of physician-ordered cholesterol screening, and provision of diet/nutrition or exercise counseling during US office-based visits by patients with hyperlipidemia. Am J CardiovasC Drugs 2010, 10(2):105-8.

18. Santos RD, Waters DD, Tarasenko L, et al: Low- and high-density lipoprotein cholesterol goal attainment in dyslipidemic women: The Lipid Treatment Assessment Project [L-TAP] 2. Am Heart J 2009, 158(5):860-6.

19. Cho L, Hoogwerf B, Huang J, Brennan DM, Hazen SL: Gender differences in utilization of effective cardiovascular secondary prevention: a Cleveland clinic prevention database study. J Womens Health [Larchmt] 2008, 17(4):515-21.

20. Mark TL, Axelsen KJ, Mucha L, Sadkova Y: Racial differences in switching, augmentation, and titration of lipid-lowering agents by Medicare/ Medicaid dual-eligible patients. Am J Manag Care 2007, 13(Suppl 3):S72-9.

21. Mensah GA, Mokdad AH, Ford ES, et al: State of disparities in cardiovascular health in the United States. Circulation 2005, 111(10):1233-41.

22. O'Meara JG, Kardia SL, Armon JJ, et al: Ethnic and sex differences in the prevalence, treatment, and control of dyslipidemia among hypertensive adults in the GENOA study. Arch Intern Med 2004, 164(12):1313-8.

23. Ferdinand $K C$, Clark LT, Watson KE, et al: Comparison of efficacy and safety of rosuvastatin versus atorvastatin in African-American patients in a six-week trial. Am J Cardiol 2006, 97(2):229-35;

24. Fong RL, Ward HJ: The efficacy of lovastatin in lowering cholesterol in African Americans with primary hypercholesterolemia. Am J Med 1997, 102(4):387-91.

25. Mostaghel $E$, Waters $D$ : Women do benefit from lipid lowering: latest clinical trial data. Cardiol Rev 2003, 11(1):4-12.

26. Chan DC, Shrank WH, Cutler D, et al: Patient, physician, and payment predictors of statin adherence. Med Care 2010, 48(3):196-202.
27. Litaker D, Koroukian SM: Racial differences in lipid-lowering agent use in Medicaid patients with cardiovascular disease. Med Care 2004, 42(10):1009-18.

28. Brookhart MA, Patrick AR, Schneeweiss S, et al: Physician follow-up and provider continuity are associated with long-term medication adherence: a study of the dynamics of statin use. Arch Intern Med 2007, 167(8):847-52.

29. Mann DM, Allegrante JP, Natarajan S, et al: Predictors of adherence to statins for primary prevention. Cardiovasc Drugs Ther 2007, 21(4):311-6.

30. McGinnis B, Olson KL, Magid D, et al: Factors related to adherence to statin therapy. Ann Pharmacother 2007, 41(11):1805-11.

31. Yilmaz MB, Pinar M, Naharci l, et al: Being well-informed about statin is associated with continuous adherence and reaching targets. Cardiovasc Drugs Ther 2005, 19(6):437-40.

32. Casebeer $L$, Huber $C$, Bennett $N$, et al: Improving the physician-patient cardiovascular risk dialogue to improve statin adherence. BMC Fam Pract 2009, 10:48.

33. Gibson TB, Mark TL, Axelsen K, et al: Impact of statin copayments on adherence and medical care utilization and expenditures. Am J Manag Care 2006, 12:SP11-9.

34. Sedjo RL, Cox ER: Lowering copayments: impact of simvastatin patent expiration on patient adherence. Am J Manag Care 2008, 14(12):813-8.

35. Chernew ME, Shah MR, Wegh A, et al: Impact of decreasing copayments on medication adherence within a disease management environment. Health Aff [Millwood] 2008, 27(1):103-12.

36. Hartz I, Sakshaug S, Furu K, et al: Norwegian counties with high, average and low statin consumption - an individual-level prescription database study. BMC Clin Pharmacol 2007, 7:14.

37. Hayward RA, Krumholz H, Zulman DM, Timble JW, Vijan S: Optimizing statin treatment for primary prevention of coronary artery disease. Ann Intern Med 2010, 152:69-77.

38. Grant RW, O'Leary KM, Weilburg JB, Singer DE, Meigs JB: Impact of concurrent medication use on statin adherence and refill persistence. Arch Intern Med 2004, 164(21):2343-8.

39. Chapman RH, Benner JS, Girase P, et al: Generic and therapeutic statin switches and disruptions in therapy. Curr Med Res Opin 2009, 25(5):1247-60.

40. Becker DM, Yanek LR, Johnson WR Jr, et al: Impact of a community-based multiple risk factor intervention on cardiovascular risk in black families with a history of premature coronary disease. Circulation 2005, 111(10):1298-304.

\section{Pre-publication history}

The pre-publication history for this paper can be accessed here: http://www.biomedcentral.com/1471-2261/11/58/prepub

doi:10.1186/1471-2261-11-58

Cite this article as: Turner et al:: A Retrospective Cohort Study of the Potency of lipid-lowering therapy and Race-gender Differences in LDL cholesterol control. BMC Cardiovascular Disorders 2011 11:58.

\section{Submit your next manuscript to BioMed Central and take full advantage of:}

- Convenient online submission

- Thorough peer review

- No space constraints or color figure charges

- Immediate publication on acceptance

- Inclusion in PubMed, CAS, Scopus and Google Scholar

- Research which is freely available for redistribution

Submit your manuscript at www.biomedcentral.com/submit
C Biomed Central 